\title{
In vitro Bioaccessibility of Lutein and Zeaxanthin of Yellow Fleshed Boiled Potatoes
}

\author{
Gabriela Burgos • Lupita Muñoa • Paola Sosa • \\ Merideth Bonierbale • Thomas zum Felde • Carlos Díaz
}

Published online: 3 September 2013

(C) The Author(s) 2013. This article is published with open access at Springerlink.com

\begin{abstract}
Yellow fleshed potatoes contain significant amounts of lutein and zeaxanthin but the bioaccessibility of potato carotenoids has not yet been investigated. The purpose of this study was to estimate the in vitro bioaccessibility of carotenoids provided by potato. Lutein and zeaxanthin concentrations of boiled, freeze dried and milled samples of seven yellow fleshed potato accessions were determined by HPLC before and after different steps (gastric, duodenal and micellar phase) of in vitro digestion. The gastric and duodenal digestive stability of lutein and zeaxanthin in boiled tubers of the different accessions ranged from 70 to $95 \%$ while the efficiency of micellarization ranged from 33 to $71 \%$ for lutein and from 51 to $71 \%$ for zeaxanthin. For all accessions, amounts of lutein and zeaxanthin after micellarization were significantly lower than the original amount found in the boiled samples. The accession 701862 showed the highest bioaccessible lutein concentration $(280 \mu \mathrm{g} / 100 \mathrm{~g}, \mathrm{FW})$ and the accessions 703566 and 704218 showed the highest bioaccessible zeaxanthin concentration (above $600 \mu \mathrm{g} / 100 \mathrm{~g}, \mathrm{FW}$ ). Considering the mean potato intake in the Andes $(500 \mathrm{~g}$ per day), the accession 701862 provides $14 \%$ of the lutein intake suggested for health benefits and the accessions 703566 and 704218 provide $50 \%$ more than the suggested zeaxanthin intake.
\end{abstract}

Keywords Lutein $\cdot$ Zeaxanthin $\cdot$ Boiled potato ·

Bioaccessibility $\cdot$ Stability $\cdot$ Micellarization $\cdot$ Cooking

G. Burgos $(\bowtie) \cdot$ L. Muñoa $\cdot$ P. Sosa $\cdot$ M. Bonierbale $\cdot$ T. zum Felde International Potato Center, Av. La Molina 1895, PO. Box 1558, Lima, Peru

e-mail: g.burgos@cgiar.org

\section{Díaz}

Department of Analytical Chemistry, Food Science and Nutrition, University of La Laguna, Avda. Astrofisico Fco. Sanchez s/n 38206, La Laguna, Santa Cruz de Tenerife, Spain

\section{Introduction}

Lutein and zeaxanthin are important dietary carotenoids that are selectively taken up into the macula of the eye, where they may protect against development of age-related macular degeneration and cataracts [1]. Moreover, these compounds have been reported to have other health-promoting effects, including immunoenhancement and reduction of the risk of developing degenerative diseases such as cancer and cardiovascular diseases [2]. There is not a recommended daily intake for lutein and zeaxanthin but many studies show a health benefit for lutein supplementation at $10 \mathrm{mg} /$ day and zeaxanthin at $2 \mathrm{mg} /$ day [3].

Significant amounts of lutein have been reported in dark leafy greens, maize and egg yolk while significant amounts of zeaxanthin have been reported in wolfberries, orange pepper, red pepper and maize [4-6]. However little attention has been given to potato as a source of these carotenoids. A recent study reported that yellow fleshed potatoes have a carotenoid profile were violaxanthin, antheraxanthin, lutein and zeaxanthin are the predominant carotenoids [7]. A more recent study reported that yellow fleshed potatoes retain above $80 \%$ of zeaxanthin and lutein after boiling [8] with boiled deep yellow fleshed potatoes containing up to $1053 \mu \mathrm{g}$ zeaxanthin/100 g FW. However, the contribution of cooked potatoes to carotenoid intake will depend on the amount of potatoes consumed and on the bioavailability of the carotenoids.

Bioavailability refers to the efficiency of absorption of an ingested compound for delivery to and utilization by target tissues [9]. Carotenoid absorption requires release from the food matrix, transfer to lipid droplets and incorporation into mixed bile salt micelles during digestion, uptake and possible metabolism by enterocytes, and incorporation into chylomicroms for secretion into lymph system [10]. The bioavailability of carotenoids is affected by many factors including physiochemical properties of the carotenoid species, 
the matrix of the carotenoid source, other components of the meal, and dietary and physiological factors that affect the digestive process [11]. Furthermore, carotenoids are by nature and function subject to oxidation, which limits their stability in the product during storage, food processing and digestion, and thus their bioavailability [12].

The determination of the efficiency of micellarization of carotenoids (EOM) or in vitro bioaccessibility during simulated digestion of plant foods has been proposed as an effective tool for the initial screening of the relative bioavailability of carotenoids of candidate cultivars for in vivo studies with animals and humans [8].

In the past few years, several studies about in vitro bioaccessibility and in vitro bioavailability of carotenoids from different sources have been published e.g., spinach, lettuce, sweet corn, cassava, sweet potato, etc. [9, 13, 14]. However, to our knowledge, no reports about bioaccessibility and bioavailability of potato carotenoids have been published. The aim of this study was to estimate the in vitro digestive stability and bioaccessibility of carotenoids from yellow fleshed cooked potatoes. Knowledge on bioaccessibility of potato carotenoids is important to provide valuable information about the potential bioavailability of potato carotenoids for absorption in vivo.

\section{Materials and Methods}

Plant Material Seven Andean landrace potato accessions of Solanum tuberosum diploid Andigenum [15] from the Goniocalyx (3) and Phureja (4) groups, were obtained from the world germplasm collection at International Potato Center (CIP) for this study. Fresh field-grown tubers were obtained from experimental plots given uniform agronomic treatment in Comas, Perú, between October 2011 and February 2012.

Twelve unblemished medium sized tubers of each of the seven accessions were collected at random taking tubers from different plants and plots and were brought directly to the laboratory for sample preparation.

Sample Preparation For each accession, the 12 tubers were washed thoroughly with tap water to remove soil residue, rinsed with distilled water and placed in stainless steel pots and covered with water. Two tubers (control tubers) were used to determine the time required to cook each accession. Tubers were cooked over uniform temperature and considered cooked when a stainless steel probe could penetrate the control tubers easily. Each accession required a different time of cooking ranging between 20 and $25 \mathrm{~min}$. The cooked tubers were peeled, cut longitudinally four pieces and sliced until a representative sample of $200 \mathrm{~g}$ was obtained. Samples were immediately frozen with liquid nitrogen, kept frozen at
$-70{ }^{\circ} \mathrm{C}$, and later lyophilized, milled through a 40 mesh sieve, and stored at $-70^{\circ} \mathrm{C}$ until analysis.

In Vitro Digestion An in vitro model based on Serrano et al. [16] and Failla and Chitchumroonchokchai [9] was used. Briefly, $500 \mathrm{mg}$ of freeze dried an milled cooked potato sample was hydrated with $5 \mathrm{ml}$ of distilled water, incubated with $1 \mathrm{ml}$ of $\alpha$-amylase $(70 \mathrm{mg} / \mathrm{ml}$ phosphate buffer, $0.1 \mathrm{M}$, $\mathrm{pH}$ 6.9, Sigma A-3176) at $37^{\circ} \mathrm{C}$ for $10 \mathrm{~min}$, brought to $\mathrm{pH} 2$ and incubated with $0.3 \mathrm{ml}$ of pepsin $(300 \mathrm{mg} / \mathrm{ml} \mathrm{HCl}-\mathrm{KCl}$, $0.2 \mathrm{M} \mathrm{pH} 1.5$, Sigma P-7012) at $37^{\circ} \mathrm{C}$ for $1 \mathrm{~h}$ (gastric phase), after which it was adjusted to $\mathrm{pH} 7$ and incubated with $1.5 \mathrm{ml}$ of pancreatin $(5 \mathrm{mg} / \mathrm{ml}$ phosphate buffer, $0.1 \mathrm{M}, \mathrm{pH} 7.5$, Sigma P1750), $3.3 \mathrm{ml}$ of lipase ( $7 \mathrm{mg} / \mathrm{ml}$ phosphate buffer, $0.1 \mathrm{M}$, pH 7.5, Sigma L-3126) and $3.3 \mathrm{ml}$ of porcine bile extract (17.5 mg/ml phosphate, 0.1 M, pH 7.5, Sigma B-8631) at $37{ }^{\circ} \mathrm{C}$ during $2 \mathrm{~h}$ (duodenal phase). Then the digested samples were centrifuged at 3,000 $\times g$ during $10 \mathrm{~min}$ and the supernatants (micellar phase) were collected.

Carotenoid Extraction $500 \mathrm{mg}$ of freeze dried and milled potato samples were hydrated with $5 \mathrm{ml}$ of distilled water during $10 \mathrm{~min}$ and extracted with $30 \mathrm{ml}$ acetone (Merck KgaA, Darmstadt, Germany) in an Ultra Turrax T25 homogenizer (IKA-Werke, Wilmington, NC, USA) for $1 \mathrm{~min}$ at $21,500 \mathrm{rpm}$. Extraction was repeated until the residue was devoid of color. The extracts were transfer to petroleum ether, washed with water to remove any acetone residue and were submitted to saponification with an equivalent volume of $10 \%$ methanolic $\mathrm{KOH}$ during $4 \mathrm{~h}$ and with light protection. The recovery and washing of the saponified carotenoids were carried out with the help of diethyl ether (Merck KgaA, Darmstadt, Germany) and acetone. The samples collected after gastric and duodenal phase and after transfer in the supernatant were mixed with $120 \mathrm{ml}$ acetone, transfer to petroleum ether and saponified as decribed for non digested samples. The resulting saponified extracts were brought to a volume of $25 \mathrm{ml}$ with petroleum ether (Merck, Darmstadt, Germany).

HPLC Determination The trans-carotenoids of the saponified extracts were analyzed in triplicate by HPLC using a method described by Burgos et al. [7]. Lutein and zeaxanthin were expressed as $\mu \mathrm{g}$ per $100 \mathrm{~g}$ dry weight (DW) and converted to $\mu \mathrm{g}$ per $100 \mathrm{~g}$ fresh weight (FW) by using corresponding dry matter contents.

Statistical Analysis The effects of the gastric, duodenal and micellar phase on the lutein and zeaxanthin concentration of each accession were analyzed by ANOVA under a randomized complete block design with three replications and means were compared by Tukey's test. All statistical tests were performed using R [17]. 


\section{Results and Discussion}

The concentration of lutein and zeaxanthin in boiled tubers of the seven accessions before and after simulated gastric and duodenal digestion and micellarization is shown in Table 1. The lutein and zeaxanthin concentrations in the undigested samples of the seven accessions ranged from 65.4 to $395 \mu \mathrm{g} /$ $100 \mathrm{~g}, \mathrm{FW}$ and from 51.3 to $1,196 \mu \mathrm{g} / 100 \mathrm{~g}$, FW, respectively. These values obtained using freeze dried and milled samples are comparable to those previously reported for boiled tubers of similar yellow fleshed potato accessions analyzed directly without freeze drying and milling (from 73 to $253 \mu \mathrm{g} / 100 \mathrm{~g}$, FW for lutein and from 0 to $1,048 \mu \mathrm{g} / 100 \mathrm{~g}$, FW for zeaxanthin) [8].

For the seven accessions, the lutein and zeaxanthin concentrations showed a clear tendency to decrease after digestion in the order gastric phase $>$ duodenal phase $>$ micellar phase. While the lutein concentration of only three accessions (701862, 703566 and 705799) and the zeaxanthin concentration of only 1 accession (703566) were significantly lower after gastric phase $(p<0.05)$ (Table 1$)$; the lutein and zeaxanthin concentration of most of the accessions were significantly lower after the duodenal phase $(p<0.05)$ (Table 1). These results indicate that lutein and zeaxanthin from potatoes are less stable under the duodenal environment than under the gastric environment.

The bioaccessible lutein and zeaxanthin (i.e., amounts transferred into the supernatants after in vitro digestion) of all the accessions was significantly lower than the original amount found in the undigested sample $(p<0.05)$ (Table 1$)$ with bioaccessible lutein ranging from 21 to $280 \mu \mathrm{g} / 100 \mathrm{~g}$, FW and bioaccessible zeaxanthin ranging from 31 to $665 \mu \mathrm{g} /$
$100 \mathrm{~g}, \mathrm{FW}$. It has been pointed out that carotenoids may also be accessible in the large intestine due to the interaction with colonic microflora [12]. Hence, the present values for the micellar phase should be interpreted in terms of bioaccessibility in the small intestine and not as total bioaccessibility in the whole intestine.

The digestive stability and the EOM of lutein and zeaxanthin from boiled potatoes is represented in Fig. 1a and b, respectively. Gastric and duodenal stability represents the percentage of carotenoid recovered after simulated gastric and small intestinal digestion respectively, including food matrix liberation; and the EOM or in vitro bioaccessibility represents the percentage of the carotenoid present in the food that was transferred to the filtered aqueous fraction during simulated digestion and that is available for absorption in the gut.

The gastric and duodenal digestive stability of lutein and zeaxanthin in the boiled yellow fleshed potatoes evaluated in this study ranged from 70 to $95 \%$ (Fig. 1a and b). Similarly, Granado-Lorencio et al. [13] found that the stability of lutein and zeaxanthin of sweet corn and red pepper after gastric and duodenal phase was relatively high (>80\%); and Chitchumroonchokchai et al. [18] found that the recovery of lutein after simulated gastric and small intestinal phases of digestion of a spinach meal varied between 70 and $88 \%$.

The chromatographic profile after gastric and duodenal phase was similar to that obtained in the boiled potatoes before digestion. No new peaks or increase of other peaks were observed. Granado-Lorencio et al. [13] reported that the chromatographic profiles after duodenal phase of green and non green vegetables were qualitatively the same as initially presented in the different vegetables, but with lower amounts

Table 1 Concentration of lutein and zeaxanthin in boiled potatoes of seven yellow fleshed accessions before and after in vitro digestion and micellarization

\begin{tabular}{|c|c|c|c|c|c|c|c|c|c|}
\hline \multirow{2}{*}{$\begin{array}{l}\text { CIP } \\
\text { number }\end{array}$} & \multirow{2}{*}{$\begin{array}{l}\text { Accession } \\
\text { name }\end{array}$} & \multicolumn{4}{|c|}{ Lutein $(\mu \mathrm{g} / 100 \mathrm{~g}, \mathrm{FW})^{*}$} & \multicolumn{4}{|c|}{ Zeaxanthin $(\mu \mathrm{g} / 100 \mathrm{~g}, \mathrm{FW})^{*}$} \\
\hline & & $\mathrm{BP}^{1}$ & $\mathrm{GP}^{2}$ & $\mathrm{DP}^{3}$ & $\mathrm{MP}^{4}$ & $\mathrm{BP}^{1}$ & $\mathrm{GP}^{2}$ & $\mathrm{DP}^{3}$ & $\mathrm{MP}^{4}$ \\
\hline 701862 & Amarilla Tumbay & $395.7^{\mathrm{a}} \pm 10.6$ & $367.1^{\mathrm{b}} \pm 16.1$ & $319.6^{\mathrm{c}} \pm 12.1$ & $280.6^{\mathrm{d}} \pm 9.7$ & $51.3^{\mathrm{a}} \pm 1.6$ & $46.4^{\mathrm{a}} \pm 3.4$ & $39.1^{\mathrm{a}} \pm 3.4$ & $31.5^{\mathrm{a}} \pm 1.4$ \\
\hline 702472 & Amarilla del Centro & $168.4^{\mathrm{a}} \pm 4.1$ & $152.9^{\mathrm{a}} \pm 5.9$ & $126.0^{\mathrm{b}} \pm 6.2$ & $106.9^{\mathrm{b}} \pm 5.4$ & $697.1^{\mathrm{a}} \pm 14.6$ & $667.7^{\mathrm{a}} \pm 22.3$ & $584.9^{\mathrm{b}} \pm 18.2$ & $470.2^{c} \pm 26.0$ \\
\hline 703282 & Ishkupuru & $263.2^{\mathrm{a}} \pm 13.5$ & $245.0^{\mathrm{a}} \pm 6.6$ & $210.7^{\mathrm{b}} \pm 4.6$ & $185.2^{\mathrm{c}} \pm 16.9$ & $66.6^{\mathrm{a}} \pm 5.9$ & $52.9^{\mathrm{a}} \pm 3.9$ & $42.5^{\mathrm{a}} \pm 3.0$ & $38.2^{\mathrm{a}} \pm 2.2$ \\
\hline 703566 & Unknown & $155.7^{\mathrm{a}} \pm 5.4$ & $134.1^{\mathrm{b}} \pm 3.4$ & $132.0^{\mathrm{b}} \pm 4.7$ & $99.7^{\mathrm{c}} \pm 6.6$ & $1196.2^{\mathrm{a}} \pm 32.1$ & $1085.9^{\mathrm{b}} \pm 32.8$ & $1033.8^{\mathrm{b}} \pm 59.7$ & $665.4^{\mathrm{c}} \pm 39.4$ \\
\hline 704218 & Yema de Huevo & $65.4^{\mathrm{a}} \pm 2.5$ & $58.6^{\mathrm{a}} \pm 5.8$ & $49.0^{\mathrm{a}} \pm 4.0$ & $21.7^{\mathrm{b}} \pm 2.9$ & $1106.1^{\mathrm{a}} \pm 17.6$ & $1066.0^{\mathrm{a}} \pm 39.6$ & $944.0^{\mathrm{b}} \pm 39.1$ & $608.3^{\mathrm{c}} \pm 64.5$ \\
\hline 705799 & Unknown & $295.0^{\mathrm{a}} \pm 10.6$ & $246.1^{\mathrm{b}} \pm 22.3$ & $231.7^{\mathrm{b}} \pm 3.3$ & $180.3^{c} \pm 14.4$ & $654.2^{\mathrm{a}} \pm 34.9$ & $611.3^{\mathrm{a}} \pm 25.1$ & $547.2^{\mathrm{b}} \pm 25.1$ & $463.9^{\mathrm{c}} \pm 21.4$ \\
\hline 706751 & Unknown & $132.1^{\mathrm{a}} \pm 2.6$ & $98.3^{\mathrm{b}} \pm 1.7$ & $92.9^{\mathrm{b}} \pm 4.6$ & $62.5^{\mathrm{c}} \pm 5.9$ & $682.7^{\mathrm{a}} \pm 28.2$ & $652.2^{\mathrm{a}} \pm 19.7$ & $575.1^{\mathrm{b}} \pm 27.1$ & $404.1^{\mathrm{c}} \pm 56.1$ \\
\hline \multicolumn{10}{|c|}{${ }^{1}$ non digested boiled potatoes (BP) } \\
\hline \multicolumn{10}{|c|}{2 gastric phase (GP) } \\
\hline \multicolumn{10}{|c|}{${ }^{3}$ duodenal phase (DP) } \\
\hline \multicolumn{10}{|c|}{${ }^{4}$ micellar phase (MP) } \\
\hline
\end{tabular}


Fig. 1 Gastric and duodenal stability and efficiency of micellarization or bioaccessibility of $\mathbf{a}$ lutein and $\mathbf{b}$ zeaxanthin after in vitro digestion (expressed as a percentage of directly extracted cooked, freeze dried and milled potato). $\mathrm{GP}=$ gastric phase, $\mathrm{DP}=$ duodenal phase, $\mathrm{MP}=$ micellar phase
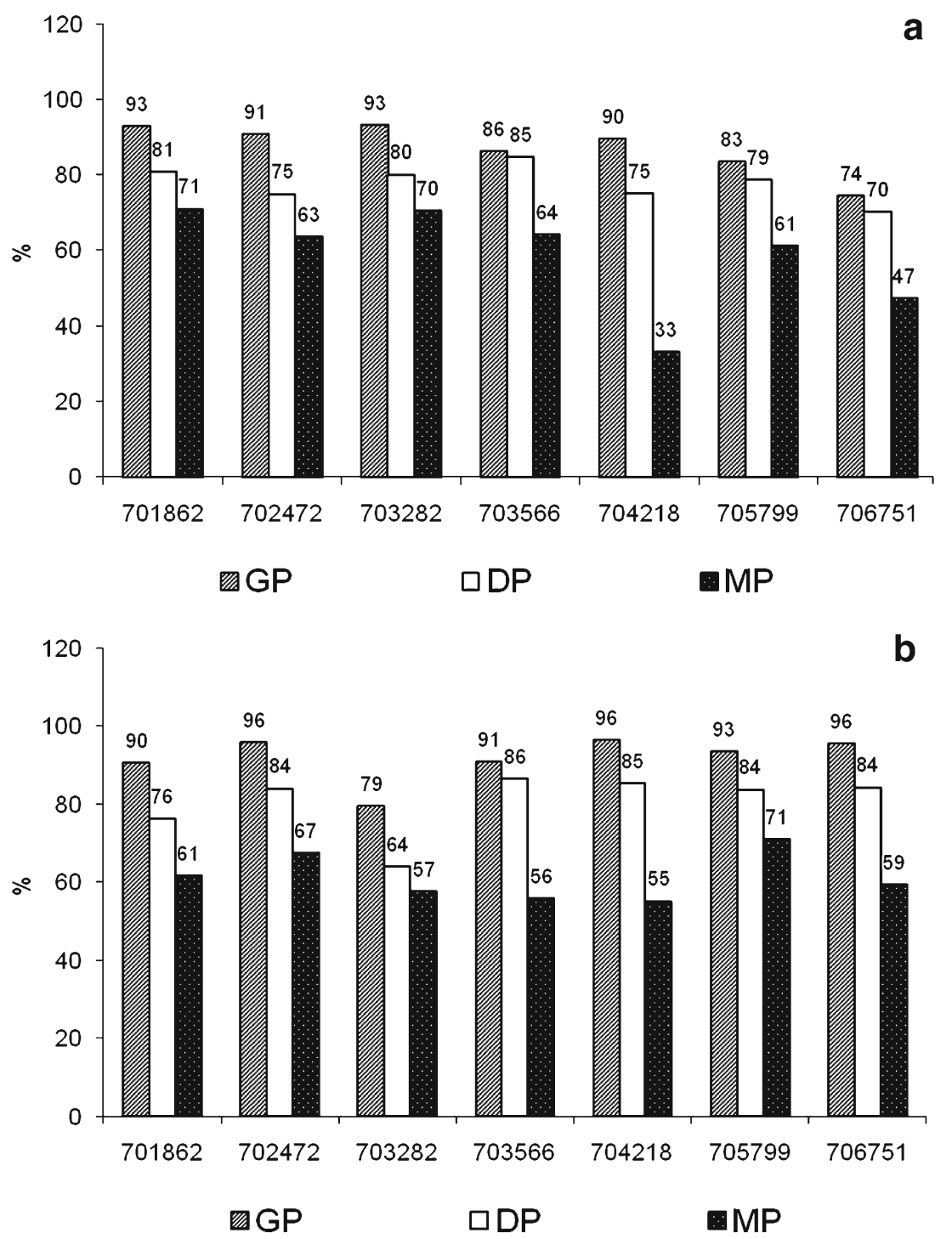

of ester forms and greater amounts of the corresponding free xanthophylls. As we saponified our samples before and after digestion, it was not possible to establish if there were differences in the amount of ester forms. However, it is important to mention that while the vegetable samples of GranadoLorencio et al. [13] had between 10 and $84 \%$ free xanthophylls, the potato samples used in this study and analyzed before digestion without saponification had more than $95 \%$ free xanthophylls (results not shown).

The EOM of the carotenoids in the accessions evaluated here ranged from 33 to $71 \%$ for lutein and from 51 to $71 \%$ for zeaxanthin (Fig. 1a and b). The accessions 701862 and 703282 that showed the highest EOM of lutein (above $70 \%$ ), had a lutein concentration 8- and 4-fold higher than the zeaxanthin concentration and the accession 704218, which showed the lowest EOM of lutein (33\%), had a lutein concentration 17 times lower than the zeaxanthin concentration. It was also observed that the accession 705799 that showed the highest EOM of zeaxanthin had a zeaxanthin concentration 2fold higher than the lutein concentration while the accession 704218 that showed the lowest EOM of zeaxanthin had a zeaxanthin concentration 17 fold higher than the lutein concentration. Based on these observations, the differences in the EOM of lutein and zeaxanthin between potato accessions could be attributed to possible interactions of carotenoids during micellarization.

The mean value for the EOM in potato was $59 \%$ for lutein and $61 \%$ for zeaxanthin. These values are similar to the EOM reported for in vitro digested sweet corn and carrot (59 and 66\% for lutein; and 54 and $48 \%$ for zeaxanthin, respectively) [13] and higher than the EOM reported for spinach (5 and $18 \%$ for lutein according to Granado-Lorencio et al. [13] and O'Conell et al. [19], respectively). The differences in EOM of lutein between potato and spinach can be explained by the differences in the intracellular location of carotenoids. In leaves, carotenoids are present in chloroplast, whereas in fruits and roots, carotenoids are 
located in chromoplast leading to the speculation that chloroplast may be less efficiently disrupted in the intestinal tract than chromoplast [20]. Differences in the EOM may be dependent also on the form in which carotenoid are present in the matrix. In green leafy vegetables, carotenoids are present as carotenoidprotein complexes while in roots and fruits they are present in a semi-crystalline form [21].

The EOM of zeaxanthin in the two potato accessions with the highest levels of this carotenoid was around $60 \%$. Chitchumroonchockchai and Failla [6], evaluated the bioaccessibility of zeaxanthin from wolfberry, orange pepper and red pepper which are considered fruit and vegetables with elevated concentrations of zeaxanthin and particularly zeaxanthin esters; and reported that the EOM of zeaxanthin in orange pepper and red pepper ranged from 50 to $70 \%$, whereas that from digested wolfberry was only $24 \%$.

The accession 701862 showed the highest bioaccessible lutein concentration $(280 \mu \mathrm{g} / 100 \mathrm{~g}$, FW). This value is higher than the bioaccessible lutein concentration reported for broccoli and red pepper (67 and $77 \mu \mathrm{g} / 100 \mathrm{~g}$, FW, respectively). However, while the EOM we found for lutein from potato is higher than that reported for lutein from green leafy vegetables, the bioaccessible lutein concentration in accession 701862 is lower than the bioaccessible lutein concentration reported in spinach (471 $\mu \mathrm{g} / 100 \mathrm{~g}$, FW) [19].

The accessions 703566 and 704218 showed the highest bioaccessible zeaxanthin concentrations (above $600 \mu \mathrm{g} / 100 \mathrm{~g}$, FW). These values are higher than the values of bioaccessible zeaxanthin concentrations reported by Granado-Lorencio et al. [13] for red pepper and sweet corn (81 and $208 \mu \mathrm{g} / 100 \mathrm{~g}, \mathrm{FW}$, respectively) but lower than the values of bioaccessible zeaxanthin reported by Chitchumroonchockchai and Failla [6] for wolfberry, orange pepper and red pepper $(24792,18156$ and $6,783 \mu \mathrm{g} /$ 100 g, FW, respectively).

Considering the mean intake of potato in the Andes of Peru, Ecuador and Bolivia (500 g per day), the bioaccessible lutein provided by the accession 701862 can reach $\approx 1,400 \mu \mathrm{g}$, FW providing $14 \%$ of the suggested level of lutein intake for having health benefit (10 $\mathrm{mg} /$ day). Likewise, the bioaccessible zeaxanthin provided by the deep yellow fleshed accessions: 703566 and 704218 can reach $\approx 3,000 \mu \mathrm{g}$ providing $50 \%$ more than the suggested level of zeaxanthin intake ( $2 \mathrm{mg} /$ day). Furthermore, the amount of bioaccessible zeaxanthin provided by $500 \mathrm{~g}$ of the accessions 703566 and 704218 represents an amount similar to that provided by the consumption of $15 \mathrm{~g}$ of wolfberry. Since it has been reported that daily ingestion of $15 \mathrm{~g}$ of fresh wolfberries after the evening meal for 28 days increase plasma zeaxanthin concentrations of human subjects 2.5 -fold [22], it is expected that consumption of $500 \mathrm{~g}$ of deep yellow fleshed potatoes have the same effect.

Although the present results provide valuable information about the potential bioavailability of lutein and zeaxanthin from potatoes for absorption in vivo, in vitro bioaccessibility covers only the first steps in terms of what may happen in vivo. It is noteworthy to mention that since this study was performed in freeze dried and milled potato samples and particle size influence the bioaccessibility, research about bioaccessibility of potato carotenoids using fresh cooked and mashed samples is needed to confirm these results. Furthermore research regarding the utilization of lutein and zeaxanthin from potatoes is needed to claim positive health effects of eating deep yellow fleshed potatoes.

\section{Conclusions}

The digestive stability of lutein and zeaxanthin from yellow fleshed potatoes was high (70 to $95 \%$ ). The EOM was significant variable among accessions ranging from 33 to $71 \%$ for lutein and from $51 \%$ to $71 \%$ for zeaxanthin. The accession 701862 showed the highest amount of bioaccessible lutein $(280 \mu \mathrm{g} / 100 \mathrm{~g}, \mathrm{FW})$ and the accessions 703566 and 704218 showed the highest amount of bioaccessible zeaxanthin (above $600 \mu \mathrm{g} / 100 \mathrm{~g}, \mathrm{FW}$ ). Boiled potatoes of deep yellow fleshed accessions provide a significant amount of bioaccessible zeaxanthin to the human diet, especially for populations with high intake of potato.

Acknowledgment This research was partially supported by CGIAR Research Program 4: Agriculture for Improved Nutrition \& Health. We thank Walter Amoros for producing the potato tubers and Raul Eyzaguirre for statistical support.

Conflict of Interest The authors declare that there is no conflict of interest.

Open Access This article is distributed under the terms of the Creative Commons Attribution License which permits any use, distribution, and reproduction in any medium, provided the original author(s) and the source are credited.

\section{References}

1. Snodderly D (1995) Evidence for protection against age-related macular degeneration by carotenoids and antioxidant vitamins. Am J Clin Nutr 62:1448S-1461S

2. Krinsky NI, Johnson EJ (2005) Carotenoid actions and their relation to health and disease. Mol Aspects Med 26:459-516

3. American Optometric Association (2009) Diet, nutrition and eye health. http://www.aoa.org/documents/nutrition/Diet_Nutrition Eye Health booklet.pdf. Accessed 28 April 2013

4. Holden JM, Eldridge AL, Beecher GR, Buzzard MI, Bhagwat S, Davis CS, Douglass LW, Gebhardt S, Haytowitz D, Schakel S (1999) Carotenoid content of U.S. foods: an update of the database. J Food Compos Anal 12:169-196

5. Perry A, Rasmussen H, Johnson EJ (2009) Xanthophyll (lutein, zeaxanthin) content in fruits, vegetables and corn and egg products. J Food Compos Anal 22:9-15

6. Chitchumroonchokchai C, Failla M (2006) Hydrolysis of zeaxanthin esters by carboxyl ester lipase during digestion facilitates 
micellarization and uptake of the xanthophyll by Caco-2 human intestinal cells. J Nutr 136:588-594

7. Burgos G, Auqui S, Amoros W, Kimura M, Salas E, Muñoa L, Bonierbale M (2009) Total and individual carotenoid profiles in the Phureja group of cultivated potatoes: I. Concentrations and relationships as determined by spectrophotometry and high performance liquid chromatography (HPLC). J Food Compos Anal 22:503-508

8. Burgos G, Amoros W, Salas E, Muñoa L, Sosa P, Díaz C, Bonierbale M (2012) Carotenoid concentrations of native Andean potatoes as affected by cooking. Food Chem 133:1131-1137

9. Failla M, Chitchumroonchokchai C (2005) In vitro models as tools for screening the relative bioavailabitilies of provitamin A carotenoids in foods. HarvestPlus Technical Monograph 3. IFPRI and CIAT, Washington, DC

10. Failla ML, Huo T, Thakkar SK (2008) In vitro screening of relative bioaccessibility of carotenoids from foods. Asia Pac J Clin Nutr 17:200-203

11. Yeum K, Russell R (2002) Carotenoid bioavailability and bioconversion. Annu Rev Nutr 22:483-504

12. Holst B, Williamson G (2008) Nutrients and phytochemicals: from bioavailability to bioefficacy beyond antioxidants. Curr Opin Biotechnol 19:73-82

13. Granado-Lorencio F, Olmedilla-Alonso B, Herrero-Barbudo C, Pérez-Sacristán B, Blanco-Navarro I, Blázquez-García S (2007) Comparative in vitro bioaccessibility of carotenoids from relevant contributors to carotenoid intake. J Agric Food Chem 55:6387-6639

14. Tumuhimbise G, Namutebi A, Muyonga J (2009) Microstructure and in vitro beta carotene bioaccessibility of heat processed orange fleshed sweet potato. Plant Foods Hum Nutr 64:312-318
15. Ovchinnikova A, Krylova E, Gavrilenko T, Smekalova T, Zhuk M, Knapp S, Spooner D (2011) Taxonomy of cultivated potatoes Solanum section Petota: Solanaceae). Bot J Linn Soc 165:107-155

16. Serrano J, Goñi I, Saura-Calixto (2005) Determination of $\beta$-carotene and lutein available from green leafy vegetables by an in vitro digestion and colonic fermentation method. J Agric Food Chem 53:2936-2940

17. R 620 Development Core Team (2011) R: A language and environment for statistical computing. $621 \mathrm{R}$ Foundation for Statistical Computing, Vienna, ISBN: 3- 900051-07-0, 622. http://www.Rproject.org/. Accessed 7 November 2012

18. Chitchumroonchokchai C, Schwartz SJ, Failla ML (2004) Assessment of lutein bioavailability from meals and supplement using simulated digestion and Caco-2 human intestinal cells. J Nutr 134:2280-2286

19. O’Connell O, Ryan L, O’Brien N (2007) Xanthophyll carotenoids are more bioaccessible from fruits than dark green vegetables. Nutr Res 27:258-264

20. Van het Hof K, West C, Weststrate J, Hautvast J (2000) Dietary factors that affect the bioavailability of carotenoids. J Nutr 30:503506, ISSN 0022-3166

21. Ryan L, Connell O, Sullivan O, Aherne S, Brien N (2008) Micellarization of carotenoids from raw and cooked vegetables. Plant Foods Hum Nutr 63:127-133

22. Cheng CY, Chung WY, Szeto YT, Benzie IFF (2005) Fasting plasma zeaxanthin response to Fructus barbarum L. (wolfberry; kei tze) in a food-based human supplementation trial. Br J Nutr 93:123-130 